\title{
LGBTQ+ Youth Expertise on Allyship and Advocacy for Educators
}

\author{
Suraj Uttamchandani, Indiana University \\ Iona Pfingston, Chroma Youth Leader \\ Becca Smith, Chroma Youth Leader \\ Barbara Dennis, Indiana University
}

Suraj Uttamchandani is a doctoral candidate in the learning sciences at Indiana University (USA). He has been an adult participant in Chroma and Chroma's TC since January 2016. His research centers on political forms of learning, participatory forms of research, and discourse analytic methodologies. He teaches undergraduate courses on learning theory for pre-service teachers as well as for non-education majors.

Iona Pfingston first joined Chroma in summer 2016 as a junior in high school and has been a part of the Teaching Committee since learning about it later that same year. They have been involved in the TC since this time working to educate youth-serving professionals of all kinds in LGBTQ+ cultural competency. They are attending Indiana University and pursuing degrees in both Spanish linguistics and mathematics.

Becca Smith has been involved with Chroma since the 8th grade and throughout high school, and served on the Teaching Committee ever since its creation. She works to design, facilitate, and evaluate cultural competency trainings for youth-serving professionals working with LGBTQ+ youth. She is attending Smith College and plans to pursue a degree in sociology.

Barbara Dennis is a Professor of Inquiry Methodology at Indiana University. She combines activism, feminist engagements and methodological innovations to engage with people toward what matters for them. She has been involved with Chroma since its beginning.

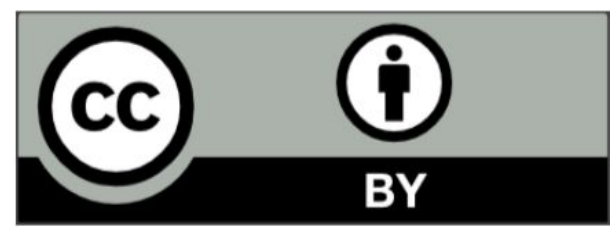

See: creativecommons.org/licenses/by/4.0 


\begin{abstract}
Summary
We discuss what we have learned as youth and adult volunteers in a youth-led, community-based LGBTQ+ youth group in the Midwest United States. Based on our experiences in schools and conversations with educators, we make a distinction between allyship for and advocacy alongside LGBTQ+ youth. We offer what we see as five important ways to promote a generative school climate for LGBTQ+ individuals. For each, we discuss what we see as the practical difference between the approaches of allies versus those of advocates. Through these ideas, we hope to engage teachers, administrators, and other youth in conversation around the importance of listening to youth expertise and experience when trying to create more inclusive classrooms and schools.
\end{abstract}

Keywords: Allyship; Advocacy; Youth Educators; LGBTQ+ Students 


\title{
LGBTQ+ Youth Expertise on Allyship and Advocacy for Educators
}

\author{
Suraj Uttamchandani, Indiana University \\ Iona Pfingston, Chroma Youth Leader \\ Becca Smith, Chroma Youth Leader \\ Barbara Dennis, Indiana University
}

Bricksburg is sometimes framed as a progressive stronghold in the conservative Midwest United States. However, its schools and youth programming are not exempt from dire national trends depicting LGBTQ+ youth's experiences in educational settings (see, for example, the most recent GLSEN School Climate Survey). ${ }^{5}$ In a survey our organization administered to 56 local LGBTQIA+ youth, 40 respondents reported that when verbal or physical harassment regarding gender identity or sexual orientation took place, the teachers and staff at their school did not intervene appropriately. It was in this climate in 2014 that Bricksburg's Chroma Youth Community was founded to provide a space for LGBTQ+ youth to socialize. Around the same time, some local students attempted to create a "straight pride" club in a local school. That effort brought into harsh focus the local school context facing LGBTQ+ youth. Chroma quickly shifted to a youth leadership model as youth began wanting to take action against such injustices. In an effort to address what they saw as insufficient educator advocacy for LGBTQ+ youth, Chroma quickly formed a youth-led Teaching Committee (TC), which created and began offering cultural competency training to youth-serving professionals locally and throughout the state.

These trainings were comprised of PowerPoint presentations offering insights on creating LGBTQ+ friendly spaces, followed by a Q\&A panel where audience members could ask more specific questions. Most significantly, the trainings were developed by youth, grounded in their own experiences, and delivered by them directly to teachers in their home districts. While this was sometimes a risky thing for youth to do, they felt strongly that intervention was necessary to improve the climate for themselves, their peers, and future LGBTQ+ students in the district. Since 2014, the TC has presented training on best practices for working with LGBTQ+ youth to over 1,500 people at the local, state, and national level.

Although audience members almost unanimously report positive learning and professional development outcomes, before attending training, Chroma youth often suggested that their teachers were not even aware that there were things they didn't know about fostering LGBTQ+ inclusive environments. From the youth's perspective, educators ranged from unaware of the issues at hand to cautiously supportive to outright hostile. Educators, however, seemed relatively unaware that they were causing damage, and although many seemed to not know what exactly they could do to provide support, few actively sought or advocated cultural competency training. We report in detail on the various opportunities and challenges associated with this

\footnotetext{
${ }^{5}$ Pseudonyms are used for the name of the town and organization.
} 
youth-led training effort in a recent paper (Dennis, Uttamchandani, Biery, \& Blauvelt, 2019). In the present article, our goal is to join a dialogue with other youth, researchers, community stakeholders, and teachers so as to understand how our views and experiences resonate, challenge, or are challenged by the efforts of others with similar goals.

Chroma youth (and others) make a distinction between allies and advocates. It is important to be a visible ally by, for example, knowing and using LGBTQ+-relevant terms correctly or displaying LGBTQ+ symbols on one's desk or door. More important, however, is to be an advocate for LGBTQ+ youth, which to us means working alongside youth to actively promote change, since LGBTQ+ youth are not always allowed to or able to advocate for themselves. When advocacy is directly informed by the experiences and voices of the LGBTQ+ youth one is advocating for, advocacy can have enormous ramifications for the well-being of these youth in a school. An ally might sympathize with a trans youth's request for a gender-neutral bathroom, listen kindly, and legitimate their needs. But an advocate will first ask the youth what they need to feel and be supported and then work with the youth to bring their perspective to the administration and make change. Ultimately, allyship is important as it provides critical emotional support to individuals. Advocacy extends that support to promote tangible change in cultures and conditions. In the remainder of this article, we (two current TC members and two Indiana University-based researchers and adult volunteers) share a list of things Chroma youth wish their teachers knew. For each item, we use the ally/advocate distinction to illustrate the ideal ways we see teachers committing to LGBTQ+ youth.

- Take youth seriously. When youth claim that they might not identify as either straight or cisgender, never diminish their identities by claiming that they are "too young" to know. This is doubly painful as it uses the youth's emergent LGBTQ+ identity alongside their status as youth as grounds to doubt their own feelings and experiences. Similarly, when youth claim that a peer, teacher, or administrator has acted in a way harmful to them, believe them. For an ally, this might mean actively listening to youth, believing them, and offering emotional support. But for an advocate, it means honoring the insights youth bring to the table and acting on them to support cultural shifts in schools - when possible and desired - by actively bringing the youth themselves into the conversation. This necessarily means unlearning the adult/youth binary that is often used to organize our classrooms.

- Understand LGBTQ+ youth as multidimensional. The LGBTQ+ youth community is large and diverse. Some youth have different needs than others. For example, issues of racism - which sometimes are amplified when combined with anti-LGBTQ+ discrimination - affect LGBTQ+ youth of color more than their white counterparts. Issues of gender-neutral bathrooms are more consequential for trans and nonbinary youth than cisgender LGB+ youth. LGBTQ+ youth are not the same as one another and 
LGBTQ+ individuals contain multitudes. Not all of their issues are interchangeable and not all of their issues are because of their LGBTQ+ identity. For an ally, it is important to not tokenize these youth and to be conversant with the many terms and definitions deployed by the LGBTQ+ community at large. For an advocate, this means committing to educational equity broadly through understanding racism, ableism, intersecting oppressions, and other forms of systemic discrimination. It also means talking to youth explicitly about what they need to have a more generative experience in school—and acting on those suggestions.

- Learn from many places. It is important for adults to draw their understanding of LGBTQ+ youth advocacy from multiple sources. If in a given discussion no youth perspectives are represented, then an important voice is being ignored and useful insights are being overlooked. On the other hand, LGBTQ+ youth are not walking encyclopedias; they should not be assumed to know everything about the LGBTQ+ community, should not be asked to speak on behalf of the whole community, and should not be asked to provide free labor and education in environments where they are supposed to be receiving services (e.g., counseling, school). Therefore, it is important for allies to learn from multiple sources, and we hope this Dialogues section becomes one such source. For advocates, this also means arranging opportunities for others to learn with you by supporting panels, professional development sessions, and community partnerships around LGBTQ+ issues. Ideally, advocates can strike a balance between creating a platform for youth to share their experiences and not relying solely on youth to provide professional development around educational issues.

- Do not "play the hero"; instead, be the advocate. While allyship can and should be personally gratifying, there are times when youth needs require advocates to feel uncomfortable or put aside that personal gratification to foreground youth's perspectives. Advocates do the right thing for youth even if it may be seen as controversial. For example, if a teacher is trying to make it easier for students to change their names on attendance rosters, they may experience pushback from administrators or staff. Similarly, sometimes parents will pressure teachers to use a student's birth name even when the student has explicitly asked for a different name to be used when discussing them. In these situations, teachers must prioritize students' needs.

- Prioritize everyone's safety over one individual's comfort. Safety includes protection from mental, emotional, and physical harm. Discomfort is a feeling of unease but does not put someone at risk for harm. A youth's personal safety should always be top priority so everyone should be safe before everyone is comfortable. For example, if a youth starts using a different set of pronouns than what they previously used, it can be uncomfortable 
or difficult for other students and teachers to adjust. However, it is an issue of personal safety for the youth to be correctly gendered. Allies and advocates alike understand that working towards equity may involve discomfort for some in the interest of safety for all.

To be clear, we value allyship and think it is important. Advocacy, then, is a way to further allyship into systemic change that will persist as students, teachers, staff, and administrators change. This list is developed based on our own experiences, so it is hyperlocal to our context. While we hope what we have offered is broadly applicable, taking cues from youth in one's local context can ensure that allyship and advocacy is locally meaningful and productive.

Fundamentally, we believe that LGBTQ+ advocacy in education requires taking youth seriously in every context. Youth are real people with knowledge, experience, and creativity even if we are young. The most important forms of allyship/advocacy can emerge from any local context. Rather than simply mapping what we have learned onto your context, consider organizing and listening to the youth in your community. Working with youth who are directly leading the efforts is the best way to ensure that allyship and advocacy are well-placed. 


\section{References}

Clemens, C. (2017). Ally or accomplice? The language of activism. Retrieved from https://www.tolerance.org/magazine/ally-or-accomplice-the-language-of -activism

Dennis, B., Uttamchandani, S., Biery, S., \& Blauvelt, A. (2019). LGBTQIA+ youth as multicultural educators. Ethnography and Education, 14(3), 360-376.

Kosciw, J. G., Greytak, E. A., Zongrone, A. D., Clark, C. M., \& Truong, N. L. (2018). The 2017 National School Climate Survey: The experiences of lesbian, gay, bisexual, transgender, and queer youth in our nation's schools. New York: GLSEN. 